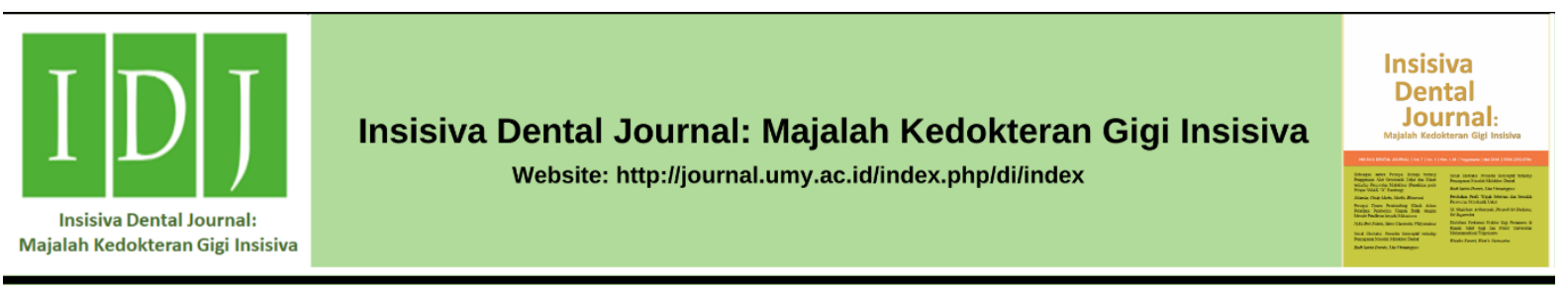

Case Report

\title{
Manajemen One Visite Restorasi Estetik pada Kasus Rudimenter Gigi Anterior
}

\author{
Management of One Visite Aaesthetic Restoration in Anterior Rudimentary Teeth Case
}

\author{
Any Setyawati* \\ Program Studi Kedokteran Gigi, Fakultas Kedokteran dan Ilmu Kesehatan, Universitas Muhammadiyah Yogyakarta, Jalan Brawijaya, \\ Tamantirto, Kasihan, Bantul, Indonesia.
}

Received date: August $16^{\text {th }}, 2020$; reviewed date: September $1^{\text {st }}, 2020$ revised date: September $24^{\text {th }}, 2020$; accepted date: October $5^{\text {th }}$, 2020 DOI : $10.18196 /$ di.9219

\begin{abstract}
Abstrak
Pendahuluan: Rudimenter merupakan kelainan bentuk gigi yaitu bentuk gigi kecil meruncing dan berukuran lebih kecil dari normal, biasanya terjadi pada gigi anterior. Hal ini sangat mengganggu penampilan pasien. Perawatan biasanya dilakukan indirect restoration dengan pemasangan mahkota dan multi visite sehingga perawatannya lama. Hal ini sering dikeluhkan oleh pasien. Tujuan: Laporan kasus ini menginformasikan bahwa kasus gigi rudimenter dapat dilakukan perawatan dengan one visite aesthethic direct restoration. Prosedur: Pasien wanita 24 tahun dengan keluhan terganggu penampilannya karena gigi 12 dan 22 mengalami rudimenter, ingin dirawat segera dan keberatan dengan kunjungan yang berulang. Manajemen dilakukan untuk menganalisa lebar mesiodistal gigi 12 dan 22 yang mengalami rudimenter dan lebar mesiodistal ruang yang tersedia pada area 12 dan 22, serta pencocokan warna dengan shade guide. Preparasi menggunakan bur terpedo untuk retensi dan resistensi. Langkah selanjutnya dilakukan pemasangan Polytetraflouroethylene (PTFE), pengaplikasian bonding, penyinaran Light Emitting Diode (LED) selama 20 detik. Pengaplikasian resin komposit warna A2 dan penyinaran LED selama 40 detik. Hasil: terlihat anomali rudimenter gigi 12 dan 22 terkoreksi, tampak bentuk anatomi gigi 22 dan 21 kembali normal. Hasil kontrol: tidak ada keluhan sakit, tampak sewarna gigi, terlihat kerapatan tepi baik, countour, embrassure dan kontak area sesuai anatomi gigi, gingiva tampak normal. Gigi dapat berfungsi dengan baik. Kesimpulan: gigi rudimenter berhasil dirawat dengan one visite esthethic direct restoration. Pasien sangat puas karena bentuk giginya menjadi normal kembali.
\end{abstract}

Kata Kunci: One Visite; Restorasi Estetik; Gigi Rudimenter

\begin{abstract}
Introduction: Rudimenter is a tooth deformity which is a small, tapered tooth shape smaller than normal, usually occurs in the anterior teeth. This is very disturbing to the patient's appearance. Treatment is usually done with indirect restoration by placing a crown and multi visite so that the treatment is long. This is often complained by patients. Aim: This case report informs that rudimentary teeth cases can be treated with one visite aesthetic direct restoration. Procedure: A 24-year-old female patient complaining of impaired appearance because teeth 12 and 22 were rudimentary, wanted immediate treatment and objected to repeated visits. Management was carried out to analyze the mesiodistal width of teeth 12 and 22 which were rudimentary and the width of the mesiodistal space available in areas 12 and 22, as well as color matching with the shade guide. Preparation uses a terpedo bur for retention and resistance. The next step is the installation of Polytetraflouroethylene (PTFE), bonding application, Light Emitting Diode (LED) for 20 seconds. Application of A2 color composite resin and LED for 40 seconds. Results: The rudimentary anomalies of teeth 12 and 22 were corrected, the anatomical shapes of teeth 22 and 21 returned to normal. Control results: no complaints of pain, tooth-colored appearance, good edge density, countour, embrassure and contact area according to tooth anatomy, gingiva looked normal. Teeth can function properly. Conclusion: Rudimentary teeth were successfully treated with one visite aesthetic direct restoration. The patient is very satisfied because his teeth are back to normal.
\end{abstract}

\footnotetext{
* Corresponding author, e-mail: any.setyawati@gmail.com
} 


\section{PENDAHULUAN}

Aesthetic restoration penting untuk menunjang fungsi klinis gigi. Aesthetic restoration merupakan seni dan sains. Aesthethic restoration merupakan restorasi yang dilakukan untuk memperbaiki estetik gigi diantaranya mengoreksi kelainan bentuk gigi menjadi normal kembali melalui suatu restorasi. Kelainan bentuk gigi, termasuk kelainan ukuran dan bentuk dapat disebabkan karena adanya gangguan pada masa pertumbuhan dan perkembangan gigi. Adanya anomali atau kelainan pada gigi dapat berupa kelainan jumlah, ukuran, dan bentuk gigi. ${ }^{1}$ Gigi rudimenter adalah kelainan gigi dengan bentuk tidak normal, yaitu gigi berbentuk seperti kerucut dan berukuran lebih kecil dari normal (pegshaped teeth). ${ }^{2}$ Gigi rudimenter termasuk ke dalam kelainan ukuran gigi yaitu mikrodonsia, dimana bentuk gigi ini secara fisik lebih kecil dari pada normalnya. Banyak sekali kasus tentang mikrodonsia, yang paling sering terjadi di insisivus lateral maksila dan molar tiga. Prevalensi mikrodonsia berkisar antara 0.8\% - 8.4\% yang biasa terjadi pada kasus klinik. Salah satu manifestasinya adalah reduksi diameter mesiodistal dan ini berkaitan dengan bentuk gigi yang rudimenter. $^{3}$ Restorasi estetik dapat menjadi salah satu pilihan untuk penatalaksanaan kasus gigi rudimenter. $^{1}$ Keluhan terbanyak dari masyarakat mengenai estetik gigi yang mempengaruhi senyuman biasanya berkaitan dengan permasalahan gigi anterior, baik itu karena karies atau kelainan perkembangan gigi. ${ }^{4}$ Pada saat gigi rudimenter lateral tumbuh, hal ini dapat mengganggu secara estetik, dan terlihat lebih kecil dibanding gigi sebelahnya, hal ini dapat diatasi dengan beberapa terapi pilihan. Dalam hal ini banyak pilihan yang dapat dilakukan diantaranya yaitu merapikan lengkung gigi, restorasi direk resin komposit, restorasi indirek dengan pembuatan mahkota jaket, ekstraksi maupun implant. Pasien kadang menginginkan perawatan yang tidak berulang dimana restorasi indirek memerlukan kunjungan yang berulang dan multi visite. Beberapa faktor dapat menjadi pertimbangan untuk dilakukan restorasi pada gigi insisivus lateral rudimenter. Restorasi pada gigi rudimenter harus dapat mengedepankan estetik dan mencegah terjadinya masalah periodonsium. Alternatif minimal intervensi prosedur adalah restorasi direk menggunakan resin komposit. ${ }^{5}$ Pada kasus gigi rudimenter biasanya dilakukan perawatan dengan pemasangan mahkota jaket untuk mengoreksi anomali yang terjadi. Laporan kasus ini bertujuan menginformasikan bahwa gigi rudimenter dapat dilakukan perawatan restorasi estetik direk menggunakan resin komposit dengan satu kali kunjungan (one visite).

\section{LAPORAN KASUS}

Pasien wanita 24 tahun dengan keluhan terganggu penampilannya (Gambar 1) karena gigi 12 (Gambar 2) dan 22 (Gambar 3) mengalami rudimenter, ingin dirawat segera dan keberatan dengan kunjungan yang berulang. Pasien telah selesai perawatan Ortho dan memasuki tahap pemakaian retainer, sehingga gigi yang akan dikoreksi bisa dibebaskan terlebih dahulu dari kawat ortho dan bracket. Mula-mula dilakukan pengukuran lebar mesiodistal gigi yang mengalami rudimenter serta lebar mesiodistal ruang yang tersedia pada area 22 dan 12 , kemudian dilakukan pencocokan warna dengan shade guide (Gambar 4) dan diperoleh warna yang sesuai dengan gigigigi di sebelahnya yaitu warna A2, selanjutnya dilakukan minimal intervensi dengan melakukan preparasi untuk membuat kekasaran pada permukaan email pada sisi mesial dan distal gigi 22 (Gambar 
5) dan gigi 12 (Gambar 6) dengan bur terpedo. Langkah selanjutnya dilakukan pemasangan polytetrafluoroethylene (PTFE) pada gigi 12 (Gambar 7) dan gigi 22 (Gambar 8), selanjutnya prosedur pengetsaan bonding generasi 7 dengan penyinaran LED selama 20 detik. Pengaplikasian resin komposit warna A2
(Gambar 9) dengan teknik layer by layer dan penyinaran LED selama 40 detik. Hasil akhir terlihat anomali rudimenter gigi 12 dan 22 terkoreksi (Gambar 10), tampak gigi 22 (Gambar 11) dan gigi 21 (Gambar 12) bentuknya kembali normal baik dari sisi contour, contact proximal dan embrassure.

\section{Sebelum perawatan:}

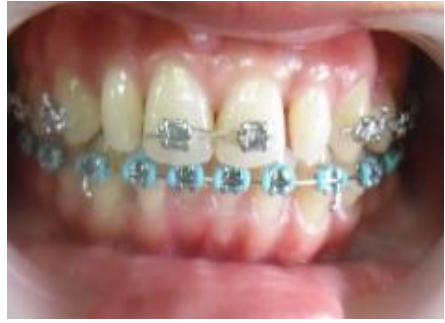

Gambar 1. Tampak depan

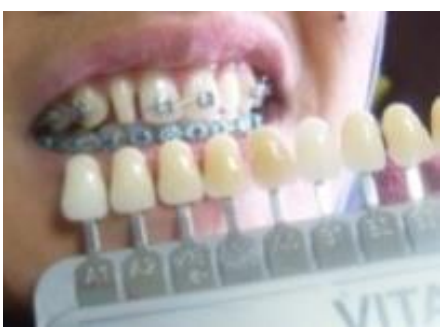

Gambar 4. Pencocokan warna

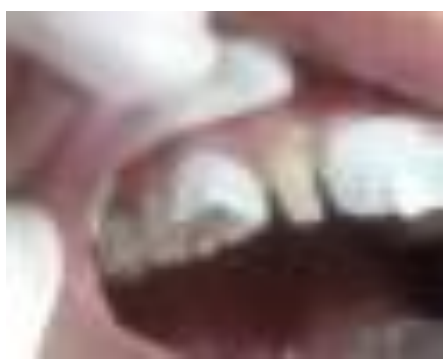

Gambar 7. PTFE pada 12

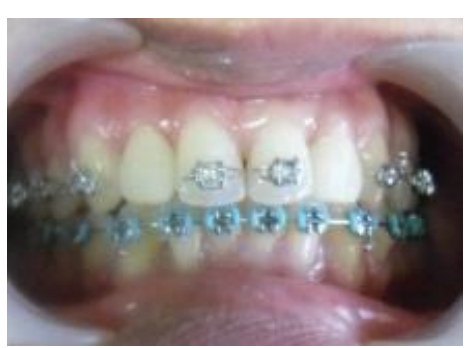

Gambar 10. Tampak depan

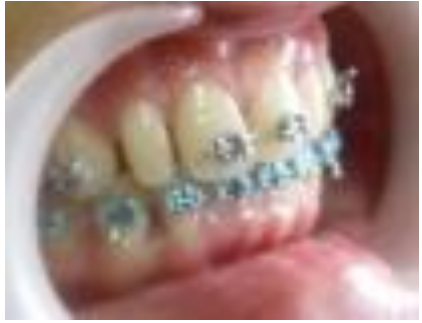

Gambar 2. Gigi 12 rudimenter

Tahapan perawatan:

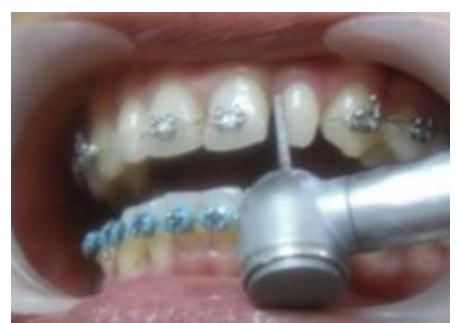

Gambar 5. Preparasi gigi 22

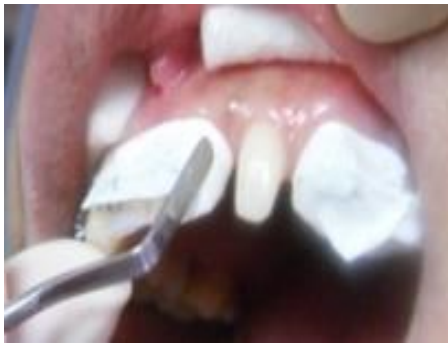

Gambar 8. PTFE pada 22

\section{Hasil Akhir:}

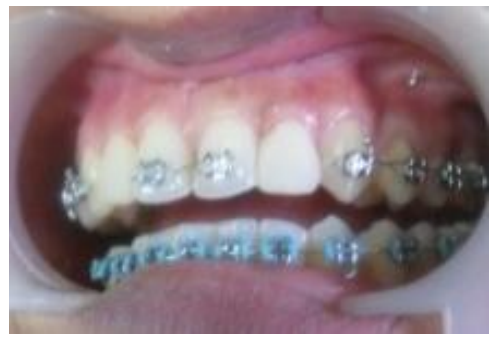

Gambar 11. Gigi 22

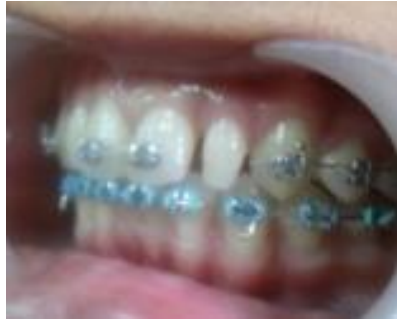

Gambar 3. Gigi 22 rudimenter

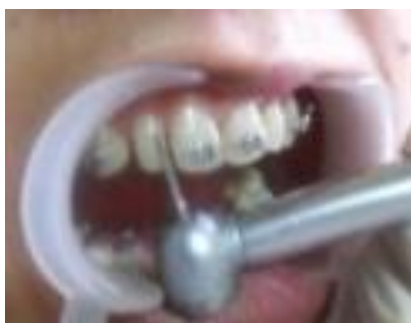

Gambar 6. Preparasi gigi 12

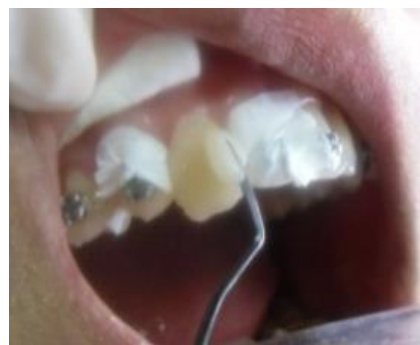

Gambar 9. Aplikasi Resin Komposit

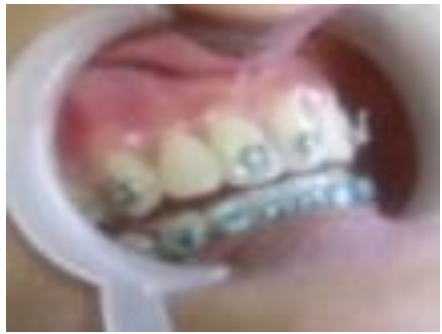

Gambar 12. Gigi 12 


\section{PEMBAHASAN}

Kasus rudimenter yang terjadi pada gigi anterior akan mengganggu penampilan terutama saat tersenyum. Senyuman adalah salah satu komponen penting dalam persepsi diri, karena senyuman dapat secara langsung menunjukkan ekspresi dan daya tarik seseorang. ${ }^{4}$

Pada kasus ini, rudimenter terjadi pada gigi 12 dan 22 sehingga sangat mengganggu penampilan terutama saat pasien tersenyum. Gigi 12 dan 22 tampak kecil meruncing, serta terdapat celah antara gigi-gigi tersebut. Celah pada gigi yang terjadi karena adanya gigi rudimenter dapat dikoreksi dengan restorasi estetik direk menggunakan resin komposit, dilakukan dengan menutup celah dan membentuk ulang bentuk anatomi gigi rudimenter yang kurang sesuai dengan bentuk anatomi gigi yaitu bentuk gigi yang meruncing dan berukuran lebih kecil dari normal. Hal ini sesuai dengan pendapat bahwa defek estetik pada gigi rudimenter gigi insisivus lateralis maksila berkaitan dengan malformasi bentuk gigi dan diastema dengan gigi sebelahnya, sehingga perawatan yang dilakukan memiliki 2 tujuan utama yaitu membentuk ulang bentuk anatomi gigi rudimenter dan menutup celah yang terjadi karena adanya gigi rudimenter tersebut. ${ }^{5}$

Pada dasarnya ada 2 cara mengisi atau menutup celah yang ditimbulkan yaitu dengan mengurangi lengkung gigi atau menambah ukuran gigi. Pada kasus ini, pilihan kedua yaitu menambah ukuran gigi menjadi lebih tepat, dimana mengisi celah tersebut dengan menambah ukuran gigi ${ }^{4}$. Pada kasus ini mengisi celah yang terjadi pada gigi rudimenter 12 dan 22 dapat mengoreksi celah yang terjadi yaitu menambah ukuran gigi dengan cara menambah ukuran lebar mesiodistal gigi 12 dan 22 serta membentuk ulang bentuk anatomi yang kurang sesuai yaitu dengan membentuk sisi ke arah labial sehinggga bentuk gigi menjadi sesuai mendekati bentuk anatomi normal gigi 12 dan $22 .{ }^{6}$

Pada kasus ini pilihan perawatannya adalah restorasi direk dengan invasif yang minimal yaitu pembentukan dengan bahan resin komposit pacakble warna $\mathrm{A} 2$ sesuai dengan pencocokan warna sebelumnya menggunakan shade guide yaitu diperoleh warn A2. Hal ini sesuai dengan pendapat bahwa terapi restorative menggunakan resin komposit menjadi pilihan klinis, sejak adanya terapi minimal invasif yang dapat meningkatkan ketahanan dari restorasi tersebut. Suksesnya restorasi adhesive direk tergantung pada formasi dan stabilitas dari lapisan hybrid. ${ }^{7}$ Pembentukan dinding mesial dan distal menggunakan polytetrafluoroethylene (PTFE). PTFE ini sangat tipis, elastis dan mudah diaplikasikan. Oleh karena sangat tipis maka bisa membentuk dinding sisi proksimal baik bagian distal maupun mesial dengan sangat rapat dengan gigi di sebelahnya. Hal ini sangat sesuai digunakan untuk kasus yang memerlukan kerapatan yang adekuat untuk dinding pada sisi proksimal. ${ }^{8}$ Pada kasus ini digunakan resin komposit untuk mengkoreksi gigi rudimenter secara direk.

Pasien membutuhkan perawatan satu kali kunjungan sehingga penggunaan resin komposit pada kasus ini sangat disarankan. Hal ini sesuai dengan pendapat bahwa penggunaan resin komposit dapat digunakan untuk kasus gigi yang mengalami anomali karena dapat membantu membentuk ulang untuk memperbaiki bentuk anatomi gigi. Resin komposit dapat mendukung secara mekanis karena mempunyai retensi tambahan melalui micromekanical interlocking dari resin tag. Material ini memiliki tekstur yang halus mengkilap setelah dilakukan finishing dan polishing pasca penumpatan sehingga bagus dari sisi estetik. ${ }^{7}$ Kelebihan penggunaan resin komposit pada kasus ini adalah minimal intervensi sehingga pengurangan jaringan gigi yang sehat bisa minimal. Pada kasus gigi dengan rudimenter yaitu bentuk gigi meruncing dan berukuran lebih kecil dari normal, maka minimal intervensi sangat diperlukan pada kasus ini karena preparasi bisa dilakukan seminimal mungkin mengurangi jaringan 
yang sehat yaitu dengan membentuk dinding yang kasar pada sisi mesial dan distal serta sedikit ke arah sisi labial untuk menambah retensi utama. ${ }^{9}$ Hal ini sesuai dengan pendapat bahwa restorasi resin komposit mempunyai kelebihan bila digunakan untuk merawat gigi yang mengalami anomali, yaitu gigi tersebut tidak perlu pengurangan atau hanya sedikit pengurangan pada email untuk menambah retensi, dimana bila tidak dilakukan preparasi maka hanya diperlukan asam fosfat untuk meningkatkan kekuatan antara email dan komposit yaitu dengan pembentukan micropit, dan dapat mempertahankan struktur email, sedangkan bila diperlukan preparasi maka dilakukan dengan minimal intervensi yaitu dengan melakukan preparasi dengan mengkasarkan sedikit permukaan email pada dinding mesial, distal serta sedikit labial. ${ }^{10}$

Resin komposit sendiri memiliki banyak kelebihan, diantaranya restorasi resin komposit menunjukkan sifat fisik, integritas marginal dan estetika yang baik. Jika dibandingkan dengan restorasi ceramic, resin komposit tidak memiliki potensi untuk mengalami fraktur yang besar akibat dari pergesekan gigi antagonis (abrassive wear). ${ }^{11}$ Restorasi gigi rudimenter indirek memiliki kelebihan yaitu stabilitas warna yang baik, bisa disesuaikan dengan warna gigi asli sehingga lebih estetis, tahan terhadap staining baik internal maupun eksternal, dan marginal fit yang dapat disesuaikan dengan anatomi gigi sehingga tepat saat diinsersikan, tetapi mempunyai kekurangan yaitu sifat abrasif yang tinggi contohnya pada bahan ceramic. Restorasi secara indirek memerlukan preparasi gigi yang cukup banyak sehingga mengurangi banyak jaringan gigi yang sehat dan memerlukan anastesi lokal dalam pengerjaannya karena dapat menimbulkan rasa nyeri pada pasien saat dilakukan preparasi. Dari sisi biaya, harganya jauh lebih mahal dibandingkan dengan restorasi direk serta memerlukan waktu kunjungan yang berulang (multi visite) karena tidak bisa dilakukan dalam satu kali kunjungan. Restorasi gigi rudimenter direk umumnya mengggunakan bahan resin komposit dan adhesive, merupakan bahan yang paling konservatif karena sedikit jaringan gigi sehat yang dikurangi, prosedur tersebut tidak membutuhkan lokal anastesi, dapat dilakukan dalam 1 kali kunjungan (one visite) dan harga yang lebih murah daripada restorasi indirek.

Kekurangan dari bahan ini adalah resin komposit berpeluang untuk terjadinya diskolorasi terutama pada pasien yang tidak bisa menjaga $\mathrm{OH}$ dan memiliki kebiasaan merokok, serta dapat terjadi kebocoran tepi restorasi seiring berjalannya waktu dalam jangka lama. Restorasi direk memiliki banyak teknik yang dapat digunakan dan dapat disesuaikan dengan kompetensi operator sehingga bisa memaksimalkan kinerja dan hasil restorasi yang didapatkan $^{12}$ Restorasi dengan bahan bonding dan resin komposit adalah perawatan yang ideal untuk gigi rudimenter. Walaupun termasuk dalam teknik yang konservatif, bahan tersebut bisa langsung diaplikasikan ke gigi. Pemilihan teknik dan bahan restorasi tergantung kepada indikasi setiap kasus, kondisi objektif gigi pasien, kemampuan teknis operator, derajat motivasi, kondisi dental pasien, kebiasaan pasien dalam menjaga kebersihan gigi dan mulut, dan tingkat sosial-ekonomi pasien. ${ }^{13}$

Berdasarkan

pertimbangan kelebihan dan kekurangan resin komposit serta kondisi pasien maka untuk kasus ini dilakukan restorasi estetik secara direk satu kali kunjungan.

\section{KESIMPULAN}

Perawatan one visite restorasi estetik direk menggunakan resin komposit dapat menjadi pertimbangan dalam merawat kasus gigi rudimenter karena secara estetik dapat langsung terkoreksi baik dari sisi bentuk anatomi gigi dan warna gigi, dapat dilakukan dalam satu kali kunjungan sehingga lebih efisien dari sisi 
waktu kunjungan dan secara biaya, pasien puas dengan hasil perawatan.

\section{DAFTAR PUSTAKA}

1. Limothai P, Leevailoj C. Aesthetic treatment of anterior spacings in a patient with localized microdontia using no-prep veneers combined with periodontal surgery: A clinical report. M Dent J. 2019;39:115-125.

2. Deshpande A, Macwan C. Research and Reviews: Journal of Dental Sciences. 2013;1(3):4.

3. Kiran S. Aesthethic Correction of Microdontia with Composite Resin Bonding Technique. IJDDMR. 2015;4(2):274-276.

4. Alberton SB, Alberton V, de Carvalho RV. Providing a harmonious smile with laminate veneers for a patient with peg-shaped lateral incisors. J Conserv Dent JCD. 2017;20(3):210-3.

5. Gupta SP. Management of Anterior Spacing with Peg Lateral by Interdisciplinary Approach: A Case Report. Orthod J Nepal. 2019;9(1):6773.

6. Tirone F, Salzano S, Rolando E. Adhesive aesthetic treatment of nonsyndromic maxillary anterior microdontia in young high-demanding patients: a case series. Int $\mathrm{J}$ Esthet Dent. 2016;11(4):520-37.

7. Novais VR. Conservative Technique for Restoration of Anterior Teeth:
Clinical Case Report. J Dent Health Oral Disord Ther [Internet]. 2017;7(4):318-323.

8. Sattar MM, Patel M, Alani A. Clinical applications of polytetrafluoroethylene (PTFE) tape in restorative dentistry. $\mathrm{Br}$ Dent J. 2017;222(3):151-8.

9. Management of Peg-Shaped Lateral with New Minimal Invasive Restorative Technique - Componeer: A Case Report. Indian J Dent Adv. 2018;10(1):53-55.

10. Kulshrestha R. Interdisciplinary Approach in the Treatment of Peg Lateral Incisors. J Orthod Endod. 2016;2(1):1-5.

11. Lameira C, Mestrener SR, Pini N, Salomão FM, Pesqueira AA, Fagundes TC. Conservative Approach for Treatment of Maxillary Lateral Incisor Agenesis with the Deciduous Tooth Retained: 18-Month Follow-Up. Oper Dent. 2018;43(2):121-7.

12. Yazicioglu O. Treatment Approach for Restoring teh Peg-Shaped Incisors. JDent Department of Conservative Dent. 2016;26(1):117-123

13. Scarpelli AC, Reboucas APS, Compart T, Novaes-Júnior JB, Paiva SM, Pordeus IA. Seven-year follow-up of aesthetic alternative for the restoration of peg-shaped incisors: a case study of identical twins. Gen Dent. 2008;56(1):74-7. 